\title{
Notas complementares sobre a biologia de Rhescyntis pseudomartii Lemaire, 1980 (Lepidoptera, Adelocephalidae) ${ }^{1}$
}

\author{
Danúncia Urban ${ }^{2}$ \\ Bernardete D. Lucas de Oliveira ${ }^{2}$
}

\begin{abstract}
In this papaer immature stages of Rhescyntis pseudomartii Lemaire, 1980 are described with notes about the variation in the fourth and fifth instars.

Uma fêmea de Rhescyntis pseudomartii coletada por Olaf H.H. Mielke em Rio Vermelho, Município de São Bento do Sul, Santa Catarina, Brasil, e o conhecimento da planta hospedeira, possibilitaram o estudo das formas imaturas desta espécie. Tendo em mãos a publicação de TRAVASSOS \& FERREIRA D'ALMEIDA (1937) na qual são descritos o ovo, as larvas da primeira, segunda e quinta idades de Rhescyntis martii ( = R.pseudimartii), e sua ocorrência em folhas de Virola bicuhyba (Myristicaceae), concluimos que algumas estruturas, côres e variações de padronagem, poderiam complementar os conhecimentos sobre as mesmas.
\end{abstract}

\section{MATERIAL E MÉTODOS}

Após a postura, os ovos foram colocados em placas de Petri e levemente umedecidos. As larvas, nas primeiras idades, também mantidas em placas de Petri, foram transferidas quando nas últimas idades, para gaiolas de criação com paredes de vidro e tela, e ramos de planta hospedeira, que eram renovados diariamente.

Os desenhos foram feitos através da câmara clara de Treffenberg e as mensurações dos exemplares foram feitas quando parados para mudar o tegumento. A terminologia usada para a descrição das larvas e a posição dos escolos é de PETERSON (1962) e para a descrição da pupa é de MOSHER (1969), com pequenas modificaçōes.

\section{COMPORTAMENTO}

A fêmea ovopositou 173 ovos, durante o período de dez dias: no primeiro dia, 20 ovos; no segundo, 12; no terceiro e quarto 42; no quinto, 27 ; no sexto, sétimo e oitavo dias, 44; no nono 21 e no décimo somente 7 . Estes últimos ovos mais claros e com dobras no cório. Esta fêmea viveu mais três dias.

Os ovos permanecem fortemente colados ao substrato por uma substância esbranquiçada secretada pelas glândulas acessórias do aparelho reprodutor da fêmea.

1. Contribuição n 668 do Departamento de Zoologia da Universidade Federal do Paraná.

2. Caixa Postal, 19020, 81504 Curitiba PR 
Ao emergir, algumas larvas comem todo o cório ao passo que outras, deixam no mesmo apenas a abertura feita para a eclosão. Ao final da primeira idade foram registrados alguns casos de canibalismo. De um modo geral, as larvas andam muito durante o dia porém, ao mudar para a segunda idade, permanecem presas à folha da planta hospedeira pelos larvópodos. Na segunda idade, a larva movimenta muito os escolos metanotais e o do oitavo segmento abdominal; quando em repouso, permanece sobre a nervura principal da folha, na face dorsal, dando a impressão de fazer parte da mesma, e com a porção anterior do corpo levemente arqueada, com os escolos metanotais sobre o dorso e para trás e o do oitavo segmento abdominal sobre o dorso porém, para à frente e os escolos pronotais para à frente, em linha reta, cobrindo a metade da cabeça. Após a muda, a larva come a exúvia, começando pelos escolos. Nas idades seguintes, as larvas permanecem em repouso no galho, na altura da base da folha, com a cabeça para baixo e as pernas inclinadas também para baixo e bem escondidas, presas à folha só pelos larvópodos e com a parte anterior do corpo afastada e um pouco arqueada. Na quinta idade, a larva prende-se ao caule da planta hospedeira pelos larvópodos anais e abdominais posteriores e começa a comer um dos lados da folha, atê a nervura principal; depois de atingir uma certa distância, corta também esta nervura para assim poder dobrar a folha e continuar comendo do mesmo lado; come mais uma parte da folha e faz novo corte na nervura (dois ou três cortes) chegando ao ápice, continua comendo o outro lado, inclusive o que sobrou da nervura. Prepara-se para empupar deixando de comer e prendendo-se ao caule ou ao pecíolo apenas pelos larvópodos anais, perde muito líquido e elimina inúmeros bolos fecais; os escolos pronotais tornam-se mais flexíveis tomando nova forma, para cima e torcidos para trás, não mais para à frente sobre a cabeça. Mais tarde, os escolos pronotais tornam-se enegrecidos e com a metade do comprimento; as prépupas, aos poucos, se imobilizam e endurecem.

A duração mínima do período embrionário foi de doze dias, e das larvas em atividade foi de trinta e nove dias, assim distribuidos: 5 dias na primeira idade; 8 dias na segunda, 10 dias na terceira e 8 na $4^{\mathrm{a}}$ e $5^{\mathrm{a}}$ idades.

\section{DESCRIÇÕES}

Larva da primeira idade - (Figs 1-4) Cabeça marrom-avermelhada, mais escura junto aos ocelos e peças bucais, com o rebordo posterior preto. Tegumento vermelho-alaranjado no dorso, mais avermelhado na linha média desde o mesonoto até o oitavo segmento abdominal; no pronoto, muito mais claro e tingido com amarelo e de um verde muito claro na porção distal do abdome. Lateralmente, marromescuro, esta cor tendendo para cinza ventralmente. O vermelho do dorso prolonga-se em cada segmento até envolver o espiráculo, de trás para a frente. Pernas pretas. Larvópodos de um cinza-esverdeado na base, placa subapical marrom e planta amarelo-ocre com frizo marrom próximo à palca subapical. Abdome com os útimos segmentos apresentando nбdoas enegrecidas laterais e na placa supra-anal. $\mathrm{O}$ tegumento dos escolos fosco e densamente micro-espiculado, provido apicalmente de uma longa cerda grossa com as micro-espículas maiores e mais dispersas na área basal; na porção distal, a cerda passa a ser achatada e levemente clavada com as micro-espículas apenas no bordo. Protórax com dois pares de escolos na placa prono- 
tal, os dorsais de um marrom-escuro passando a bruno-avermelhado no meio e quase tão longos quanto a altura do segmento, divergindo da base para o ápice, bifurcadas distalmente no sentido ântero-posterior, com o ramo anterior tambêm bifurcado e a cerda do ramo posterior maior que as demais e igualando o próprio escolo; e os supra-espiraculares também marrons, curtos, levemente bifurcados, porém com duas cerdas apicais, uma anterior e outra posterior, divergentes; com chalaças pretas sub-espiraculares e látero-ventrais, com duas cerdas finas em cada; posteriormente aos escolos dorsais e supra-espiraculares também uma cerda fina. Mesotorax com os escolos dorsais e supra-espiraculares pretos, curtos e bifurcados no sentido ântero-posterior com uma cerda em cada ponta; chalaças sub-espiraculares e látero-ventrais pequenas e com uma única cerda preta fina. Metatórax com um par de longos escolos dorsais divergentes, maiores que o dobro da altura do proprio segmento, marrons no quinto basal e no apical e de um amarelo-claro no restante, bifurcados no sentido lateral e com uma cerda grossa em cada ponta; escolos supra-espiraculares e chalaças sub-espiraculares e látero-ventrais como no mesotórax. Primeiro ao quinto segmento abdominal com os escolos dorsais e sub-dorsais muito próximos, o dorsal maior e mais para a base do segmento, preto na área proximal e marrom-claro no ápice, seguido de perto pelo sub-dorsal inteiramente preto e muito reduzido, cada escolo com uma cerda apical grossa; os escolos supra-espiraculares pouco maiores que os sub-dorsais. No sexto segmento os dorsais e supraespiraculares um pouco menores e no sétimo bastante reduzidos, tanto os escolos como as cerdas apicais e os sub-dorsais com cerda fina e lisa. Do primeiro ao sétimo segmento, as chalaças sub-espiraculares e látero-ventrais muito próximas entre si e com uma cerda fina e lisa, no oitavo as chalaças mais afastadas. Oitavo segmento abdominal com um único escolo dorsal, mediano, tão longo como duas vezes a altura do segmento, como os escolos dorsais do metatórax na forma e nas cores; posteriormente ao escolo dorsal, os sub-dorsais enegrecidos com cerda apical grossa micro-espiculada como no protórax; os supra-espiraculares como no quinto segmento. Nono segmento com os escolos dorsais muito próximos entre si na base e os supraespiraculares muito reduzidos, todos com cerda grossa apical. Placa supra-anal com quatro escolos na área basal, pequenos, dois laterais e dois no ápice, todos com cerda grossa micro-espiculada e mais quatro cerdas grossas no ápice do segmento, estas lisas ou micro-espiculadas. Base do último par de larvópodos com três cerdas delgadas no ápice, micro-espiculadas ou lisas e uma cerda fina na projeção láterodorsal do larvópodo.

Após algumas horas, tornam-se evidentes as nódoas negras do segundo e terceiro segmentos torácicos, maiores no terceiro.

Quando parada para a ecdise, com $10 \mathrm{~mm}$ de comprimento, apresentam uma cor alaranjada-clara no dorso, passando para esbranquiçada no ápice do abdome e cinza com esbranquiçado no restante, e os escolos maiores com a área basal e apical preta, medianamente brancos com uma pequena área vermelha subapical.

Larva da segunda idade - (Figs. 5-9) Cabeça e pernas marrom-claro-amareladas, tingindo de alaranjado na fronte. No restante do tegumento predominando o cinza-alaranjado. De um tom alaranjado mais intenso na porção mediana do mesotórax e metatórax aos lados da estria mediana preta que se prolonga até o sétimo 


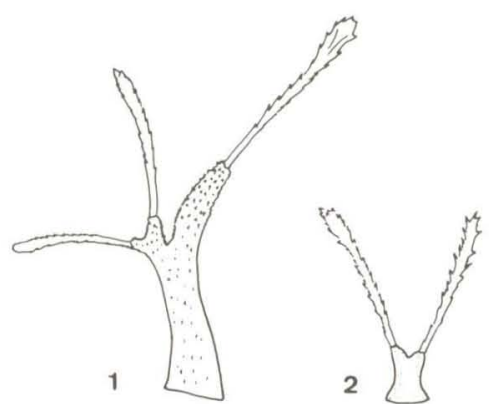

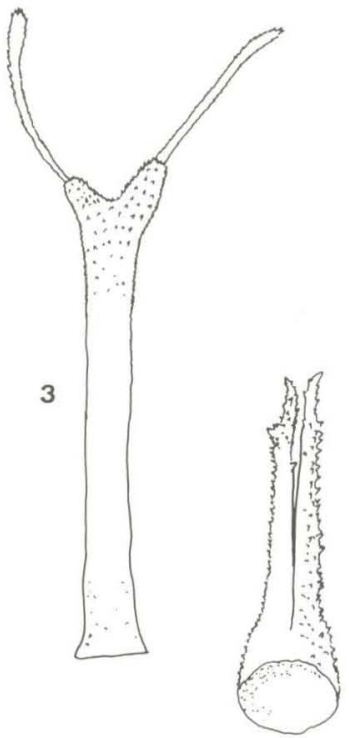

5
4

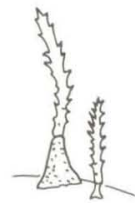

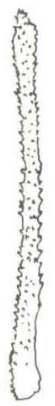

7

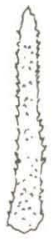

8

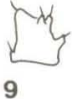

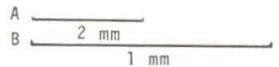

Figs. 1-9. Rhescyntis pseudomartii . Escolos das larvas de: $1^{\mathrm{a}}$ idade: 1, escolo dorsal do pronoto, visto de perfil; 2, dorsal do mesonoto; 3 , dorsal do metanoto; 4 , dorsal e subdorsal do $1^{\circ}$ tergo abdominal. $2^{\mathrm{a}}$ idade: 5 , vista ventral do escolo dorsal do pronoto evidenciando a fusão basal; 6 , ápice; 7 , dorsal do metanoto; 8 , dorsal do $8^{\circ}$ tergo abdominal; 9 , dorsal do $2 \%$ tergo abdominal.

Escala: A, para as figuras 5,7 e 8 .

segmento abdominal. Do quarto ao sétimo segmento com duas estrias pretas mais fracas próximas da mediana. Cinza-esverdeado escuro a partir do oitavo segmento, incluindo a placa supra-anal. Lado ventral dos dois primeiros segmentos abdominais cinza-alaranjados, larvópodos e lado ventral do terceiro ao sexto segmentos abdominais alaranjado muito pálido, passando para esbranquiçado no restante.

Todo o tegumento cerdoso e com pináculos castanhos, cada pináculo com uma cerda da mesma cor. Placa pronotal cinza-esverdeada e projetada para a frente em forma de dois escolos mais ou menos rígidos que formam um ângulo agudo com o corpo. Esocolos da mesma cor do tegumento, com espinhos pequenos em toda a volta e um espinho vermelho lateral na base a cada lado, subapicalmente com uma pequena bifurcação. Escolos metatorácicos e do oitavo segmento abdominal cinza- 
esverdeados com a base enegrecida e o ápice fusco com o mesmo diâmetro desde a base, porém um pouco dilatado no ápice e com uma bifurcação pouco profunda, recobertos de espinhos curtos.

Mesotórax e segmentos abdominais restantes com escolos castanhos regularmente espinhosos aos lados da estria negra, muito reduzidos no mesotórax, primeiro, sétimo, oitavo, nono e décimo segmentos abdominais sendo que no nono, muito próximos entre si e, no décimo, mais afastados. Do mesotórax ao décimo primeiro segmento abdominal com uma série de chalaças vermelhas supra-espiraculares com pequenas cerdas pretas apicais, muito reduzidas nos últimos segmentos. Segmento distal com bifurcação além da placa supra-anal, e uma cerda curva terminal voltada para fora.

Mensuraçōes: quando parada para a ecdise, com $20 \mathrm{~mm}$ de comprimento e 2 mm de largura máxima; escolos protorácicos: $5 \mathrm{~mm}$; escolos metatorácicos: $6,5 \mathrm{~mm}$ e o do oitavo segmento abdominal: $4,5 \mathrm{~mm}$.

Larva da terceira idade - (Figs. 10-14). Logo após a ecdise, a cabeça, pronoto com seus esolos, escolos metatorácicos e o do oitavo segmento abdominal, branco-cremosos; ápice do abdome com área esverdeada: estria mediana dorsal preta orlada com branco-cremoso; mesonoto com duas estrias pretas ao lado da mediana, estas estrias pouco distintas no quinto, sexto e sétimo segmentos abdominais.

Cabeça marrom-oliva com a fronte e área supra-antenal esbranquiçadas. Pernas de uma marrom-oliva mais claro que o da cabeça. Lateralmente, até o quarto segmento abdominal e ventralmente nos dois primeiros segmentos abdominais o tegumento vináceo-cinza, tomando uma tonalidade alaranjado-cinza para o dorso. Estria preta dorsal orlada por duas estrias mais finas cremosas e outras duas, menos distintas, pretas como a mediana que é interrompida pelo escolo do oitavo segmento abdominal.

Tegumento com pequenas cerdas marrom-claras e pináculos marrons como na idade anterior. Larvópodos e lado ventral a partir do terceiro segmento abdominal esbranquiçados; placa subapical dos larv6podos levemente esverdeada com cerdas esbranquiçadas predominando, as cerdas pretas na porção mais dorsal dos larvópodos. Lateralmente, estria verde-clara com pináculos da mesma cor providos de pequena cerda, aumentando progressivamente do quarto até o último segmento abdominal, no sétimo e oitavo bastante mais larga envolvendo completamente os espiráculos. Placa pronotal com escolos cinza-esverdeados com pequenos espinhos, como na idade anterior; os escolos do metatórax e do oitavo segmento abdominal enegrecidos na base e no ápice, e no restante cinza-esverdeados, brilhantes e muito escuros, com espinhos curtos, eretos, em toda a volta. Mesotórax com dois pequenos tubérculos dorsais. Do segundo ao sexto segmentos abdominais com pequenos escolos dorsais espinhosos pretos, brilhantes. No oitavo segmento abdominal dois pequenos tubérculos atrás do escolo mediano; nono segmento abdominal também com dois tubérculos pretos porém, mais próximos entre si do que os do oitavo segmento. Placa supra anal cinza-esverdeada-escura e brilhante, parte dorsal dos larvópodos anais da mesma cor da placa supra anal.

Pequenas cerdas castanhas sobre todo o corpo incluindo a cabeça; larvópodos com cerdas esbranquiçadas ou prateadas. 
Revta bras. Zool.

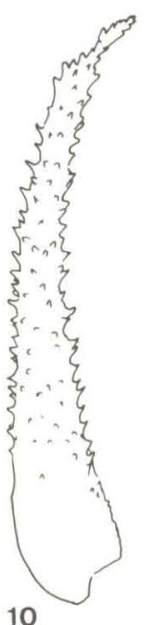

10

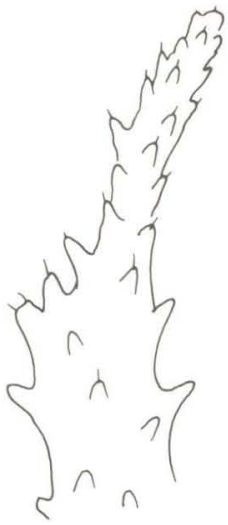

11

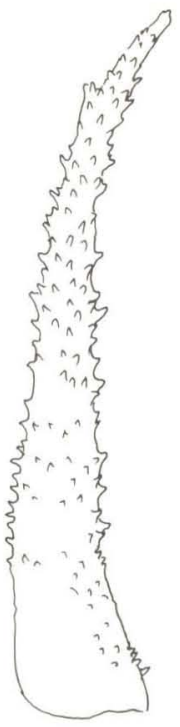

15
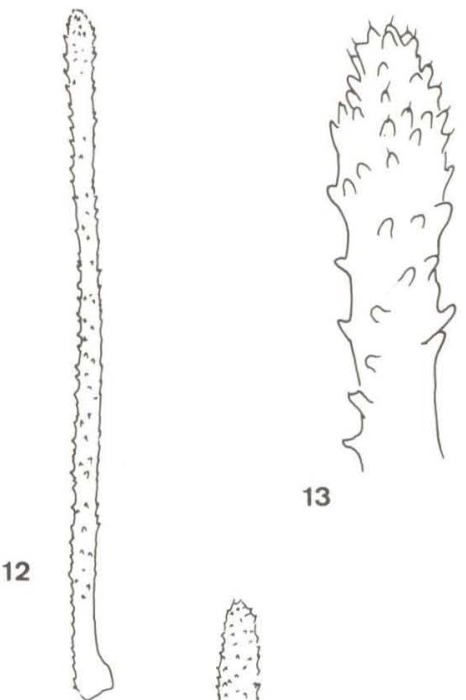

13

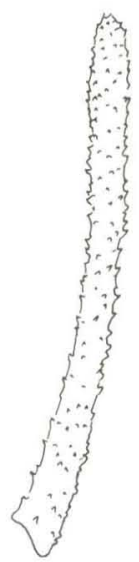

17
18

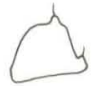

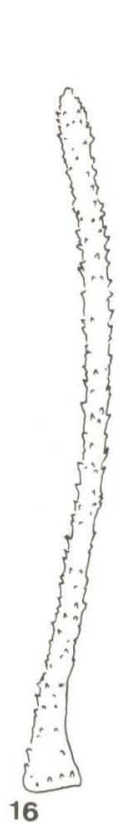

Figs. 10-18. Rhescyntis pseudomartii. Escolos das larvas de: 3a idade: 10, escolo dorsal do pronoto, de perfil; 11, ápice; 12, escolo dorsal do metanoto; 13, ápice; 14, dorsal do 8 o tergo abdominal; $4^{2}$ idade: 15 , escolo dorsal do pronoto; 16 , dorsal do metanoto; 17 , dorsal do $8^{\circ}$ tergo abdominal; 18 , dorsal do $2^{\circ}$ tergo abdominal. Escala: B, para as figuras 11,13 e 18 .

Medidas: (parada para mudar) $32 \mathrm{~mm}$; largura do primeiro segmento abdominal: $4,5 \mathrm{~mm}$. 
Larva da quarta idade - (Figs. 15-18). Ao mudar, toma a tonalidade verde clara com a linha médio dorsal amarela mais larga em todo abdome $(1 \mathrm{~mm})$ e no tórax marrom-clara e aproximadamente a metade da largura $(0,5 \mathrm{~mm})$ da anterior. $\mathrm{O}$ tegumento branco nas áreas inter-segmentais; aos lados da estria médio dorsal, estrias enegrecidas mais estreitas; nos larvópodos e ventralmente, verde-translúcido claro; escolos com o tegumento brilhante, verde-claros; espiráculos cremosos, cabeça verde-clara, fusca.

Nesta idade foi constatada variação no colorido do tegumento: inteiramente verde; com manchas marrons no quarto segmento abdominal, ou com manchas marrons no ápice do terceiro e no quarto segmentos. Nas manchas escuras, com chalaças enegrecidas com amarelo no meio e, nas proximidades das manchas, as chalaças mais claras.

Cabeça verde-amarelado-clara, fusca e com mancha irregular fusca ao longo dos epicrânios; escolos pronotais verde-oliva-claros no lado dorsal, verde-claros lateralmente e de um oliva-enegrecido no lado ventral, brilhantes e com espinhos curtos em volta, como nas idades anteriores; escolos metanotais enegrecidos dorsalmente e verde-oliva no lado ventral, com os espinhos um pouco decumbentes, também em toda a volta; escolo do oitavo segmento abdominal mais claro do que o metanotal.

O tegumento predominantemente verde-amarelado, com estria amarela médio-dorsal orlada com estrias mais delgadas enegrecidas; no mesotórax e metatórax marrom-claro medianamente em vez de amarelo e com estrias pretas mais estreitadas. Verde-esbranquiçado nos esternos, a partir do terceiro segmento abdominal. Metanoto e primeiro segmento abdominal com manchas marrons de contorno irregular deixando uma mancha verde aos lados do primeiro segmento. Segundo e terceiro segmentos abdominais com grande mancha enegrecida que se prolonga até o lado ventral porém, no quatro e quinto segmentos, chega até a base dos larvópodos e diminui gradativamente no sexto segmento, em direção à estria dorsal; esta mancha com estrias inclinadas, lembrando as nervuras de uma folha. Membrana intersegmental branca. Espiráculos marrom-claros. Todas as áreas escuras e a estria amarela dorsal com chalaças enegrecidas, pequenas.

Mensurações: (parada para mudar) $45 \mathrm{~mm}$ (até a ponta do escolo); escolo pronotal: $11 \mathrm{~mm}$; escolo metanotal: $12 \mathrm{~mm}$; escolo do oitavo segmento abdominal: 9 $\mathrm{mm}$.

Larva da quinta idade - Difere das larvas das idades anteriores pela ausência de escolos longos no metanoto e no oitavo segmento abdominal. Como nas idades anteriores, os larvópodos anais com duas projeções dorsais delgadas apicalmente e larga projeção lateral, distintamente enegrecida nesta idade. Placa pronotal indistinta; o pronoto anteriormente com duas projeçóes de ápice truncado, porém mais fino que na base. Placa supra-anal preta e brilhante.

Cabeça verde-clara; tegumento do restante do corpo, em grande parte, também verde-claro, porém levemente amarelado, com estria mediana no dorso do tórax e do oitavo segmento abdominal até a placa supra anal onde a estria se torna mais escura e mais largamente fundida às estrias laterais finas e também cinzentas; nos demais segmentos abdominais a estria tem a cor amarelo-cremosa medianamente e orlada por estrias finas cinzentas. Grandes manchas cinza-oliváceas nos la- 
dos do corpo, começando no primeiro segmento abdominal, alargando muito no ápice do segundo onde atinge a estria dorsal, continua larga no terceiro e quarto segmentos, diminui no quinto segmento e muito menor do sexto ao oitavo segmentos; no terceiro e quarto segmentos com manchas alaranjadas mais ou menos triangulares sendo que a base do triângulo fica junto aos larvópodos. Esbranquiçado ventralmente e nas áreas inter-segmentais.Chalaças enegrecidas e castanhas, e pináculos de um castanho mais claro nos lados do tórax, base dos larvópodos, lado ventral do primeiro, segundo, sétimo e oitavo segmentos abdominais, entre os larvópodos, nas manchas escuras e na estria dorsal, tanto na parte amarelo-cremosa com nas cinzentas.

As larvas que apresentaram quase todo o tegumento verde, na quarta idade, quando na quinta idade com o tegumento verde predominando, assemelham-se às acima descritas, porém, sem as nódoas laterais e sem as manchas alaranjadas. Outras larvas com larga estria cinza-oliva com chalaças enegrecidas, do mesotórax ao nono segmento abdominal, terminando junto à carena lateral e com expansões irregulares em direção ao dorso, pouco maiores no quarto segmento e com pequenas áreas cinzentas dorso-laterais na base dos segmentos abdominais; o restante, como na larva descrita.

Mensuraçōes: (em repouso) $80 \mathrm{~mm}$; largura no primeiro segmento abdominal: $15 \mathrm{~mm}$; altura no primeiro segmento abdominal; $12 \mathrm{~mm}$; altura no segundo segmento abdominal: $18 \mathrm{~mm}$; escolo pronotal; $5 \mathrm{~mm}$.

Dois dias após a muda, o tegumento torna-se verde ventralmente e no quarto dia toma uma tonalidade verde-azulada, tanto dorsal como ventralmente e aumentam as manchas alaranjadas. No décimo dia, as áreas inter-segmentais tendem para o alaranjado no lado dorsal e para o cinza-róseo no lado ventral.

Pré-pupa - Tegumento verde mais escuro do que o da larva e misturado com amarelo; linha médio-dorsal enegrecida; ventralmente amarelo-cremoso com as chalaças pretas menos nítidas do que na larva.

Pupa - Tegumento logo após a muda: verde-forte nas asas, antenas, cabeça, flancos do abdome na porção ventral aos espiráculos; amarelo junto à linha médioventral; cremaster marrom-enegrecido; dorsalmente amarelo tingido com verdeclaro; metanoto com duas nódoas marrons; linha lateral verde separando o tergo do esterno, um pouco ventral aos espiráculos abdominais; espiráculos torácicos marrons. O tegumento brilhante no abdome e fosco no restante. Passado algum tempo, tomam tonalidade marrom-escura. 
Vol. 6(4), 1989

\section{REFERENCIAS}

LEMAIRE, C., 1980. Les Attacidae Americains (=Saturniidae) Arsenurinae. Edition C. Lemaire, 199 pp., 76 pranchas.

MONTE, O., 1934. Borboletas que vivem em plantas cultivadas. Publ. 21, Secr. Agr. Est. Minas Gerais, 220 pp., 168 figs.

MOSHER, E., 1969. Lepidoptera pupae. Five collected works on the pupae of north American Lepidoptera Entomological Reprint Specialists. East Lansing, Michigan, 323 pp.

PETERSON, A., 1962. Larvae of Insects. An Introduction to Nearctic species. Part I., Lepidoptera and plant infesting Hymenoptera. Columbus, Ohio, USA. 315 pp.

SILVA, A. G. D'ARAUJO: C.R. GONÇALVES; D.M. GALVÃO; A.J.L. GONÇALVES; J. GOMES; M.N. SILVA \& L. SIMONI, 1968. Quarto Catálogo dos Insetos que vivem nas plantas do Brasil - seus parasitos e predadores Laboratório de Patologia Vegetal, Rio de Janeiro, I(2): 423-906; II(1): XIV + 1-622.

TRAVASSOS, L. \& R. FERREIRA D'ALMEIDA, 1937. Contribuição para o conhecimento da bionomia de alguns lepidopteros brasileiros. Mem. Inst. Osw. Cruz, Rio de Janeiro, 32(4):499-516, 2 ests. 